Title of article: „Wpływ kąta wyprzedzenia i promienia krzywizny na siły skrawania w pięcioosiowym frezowaniu powierzchni złożonych" ("Effect of the lead angle and the radius of curvature on the cutting forces in a 5-axis milling of sculptured surfaces")

Mechanik, Vol. 91, No. 1 (2018): pages 18-22

DOI: https://doi.org/10.17814/mechanik.2018.1.2

\title{
Effect of the lead angle and the radius of curvature on the cutting forces in a 5-axis milling of sculptured surfaces
}

\author{
Wpływ kąta wyprzedzenia i promienia krzywizny \\ na siły skrawania w pięcioosiowym frezowaniu powierzchni złożonych
}

\section{MICHAL GDULA JAN BUREK *}

\begin{abstract}
Experimental studies are presented, were conducted that aimed at determining the mathematical models of the influence of the lead angle and the radius of curvature of the profile of machined sculptured surface on the components of the cutting force. The object of the experimental studies was a convex and concave surface of a turbine blade of Inconel 718 alloy. The toroid cutter was used for the tests. Based on the results of the study it was found that the lead angle in the machining of the convex surface and concave turbine blade should be continuously varied with the change of radius of curvature in the direction of the machined surface profile.
\end{abstract}

KEYWORDS: 5-axis milling, cutting forces, sculptured surfaces, turbine blade

Five-axis milling technologies are currently used to produce molds and matrices as well as geometrically complex parts for the aerospace, automotive and biomedical industries. Five-axis milling - by combining three linear displacements and two additional rotary displacements allows the tool to move continuously in space in relation to the normal vector to the surface being machined. As a result, geometrically complicated shapes can be machined in one fixture, which shortens the total time of part production. In addition, the kinematic freedom of five-axis machining allows to increase the availability of the tool, and at the same time to shorten its reach. The use of a shorter tool with a geometry of a five-axis tool that has a suitably selected geometry ensures not only a higher rigidity of the machine tool-holderobject-tool, but also high surface quality and increased productivity. For this reason, in industrial practice, toroidal milling cutters are increasingly used for five-axis machining of complex surfaces [1, 4-6].

In addition to shortening the machining time, the main purpose of using five-axis milling is to increase the geometrical accuracy of the workpieces. This cannot be achieved without deriving model relationships that describe the relationship between geometric parameters of the complex surface and the kinematic orientation of the tool axis. It should be taken into account that due to continuous changes in the curvature of the composite surface during its processing, the cross-sectional area of the cutting layer can change, and consequently - the values and direction of the cutting forces' components, resulting in dimensional and shape inaccuracy.

\footnotetext{
* Dr inż. Michał Gdula (gdulam@prz.edu.pl); dr hab. inż. Jan Burek, prof PRz (jburek@prz.edu.pl) - Politechnika Rzeszowska, Wydział Budowy Maszyn i Lotnictwa, Katedra Technik Wytwarzania i Automatyzacj
}

Defining the model relationships between the mentioned parameters and the components of the cutting force becomes important.

Most research on five-axis machining focuses on generating tool paths and optimizing them. Due to the improvement of CAM technology, some geometrical limitations and errors of the program itself have been eliminated, but so far the geometrical and kinematic aspects of the five-axis milling process related to the cutting zone have not been taken into account.

One of the latest research was conducted by Ozturk et al. [1], Budak et al. [9] and Lazoglu et al. [2]. They concerned analytical and experimental modeling of the geometry of the cutting layer by a discrete direct CAD method, which allowed to obtain data, which was then used to predict the cutting force and optimize the process of five-axis milling. This article concerns the research being a continuation of those carried out by Gdula et al. [3-6], which consisted in determining the correlation of geometric and kinematic parameters in the process of five-axis milling with toroidal milling of complex surfaces of turbine blades.

\section{Five-axis milling of complex surfaces}

Compound surfaces are used to describe complex shapes of the form: convex, concave, biconvex, biconcave, concaveconvex and convex-concave. A complex surface is generally curved in both major parametric directions $-u$ and $v$. The final surface shape is characterized by the values of the main curvatures in the vicinity of the selected point $P$ on this surface. The authors adopted the main curvature as radii $\rho_{1}$ and $\rho_{2}$ (fig. 1).

One of the main problems of five-axis milling is the selection of the optimal orientation of axis of the toroidal milling cutter, relatively to the vector of the normal folded surface. The orientation of the cutter axis is defined by programming the kinematic parameters of the advance angle $\alpha$ and/or the inclination angle $\beta$ (fig. 2).

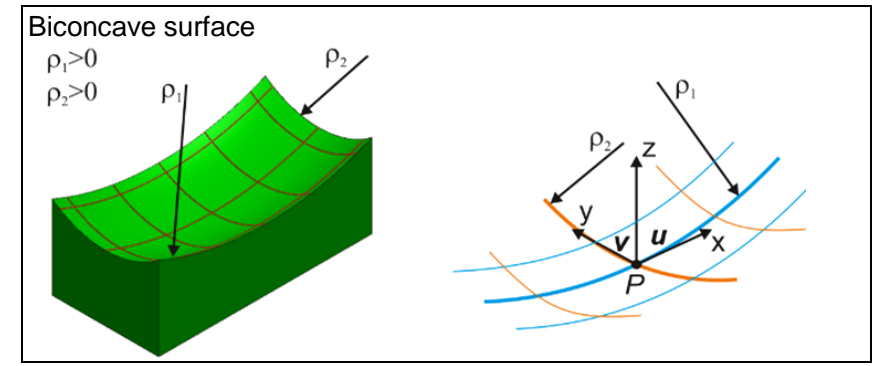

Fig. 1. Geometric parameters of complex surfaces 


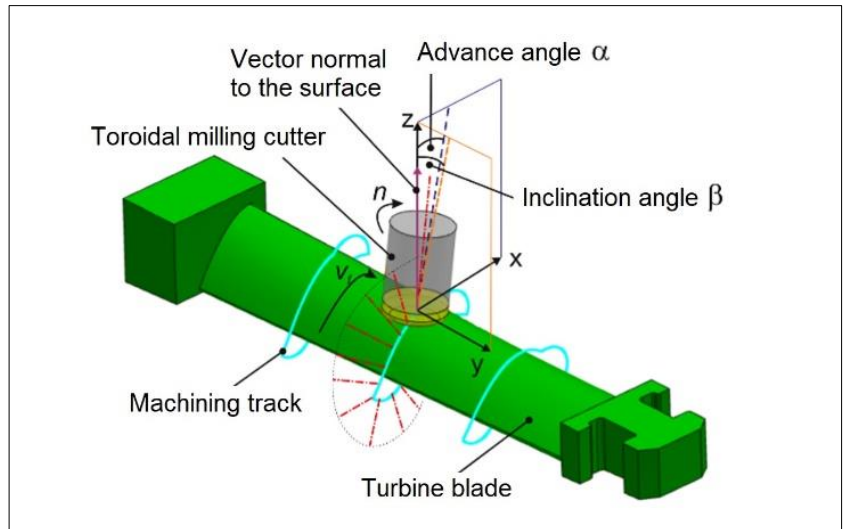

Fig. 2. Kinematic parameters of the five-axis milling process

Described parameters uniquely determine the conditions and the contact zone between the toroidal milling cutter and the machined surface [3], while - as shown in [4] - only the angle of advance $\alpha$ and the radius of curvature $\rho_{1}$ significantly affect the cross-section of the cutting layer, and these parameters were further analyzed.

\section{Cutting layer}

The geometry of the cutting layer in toroidal milling has the characteristic shape of a "comma" and the thickness of the cutting layer $h$ varies along the active cutting edge $b$, which is schematically shown in fig. 3 . In machining with a toroidal cutter, the geometry of the cutting layer is influenced by: the radius of the circular cutting insert $r_{p}$, feed per cutting edge $f_{z}$ and axial infeed $a_{p}$ [3-5].

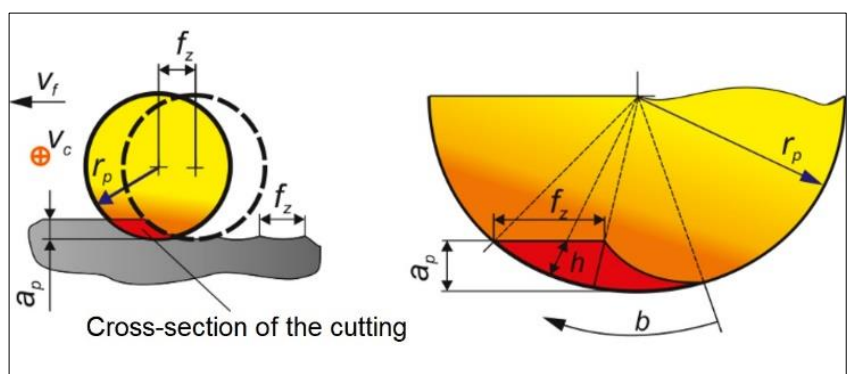

Fig. 3. Geometry of the cutting layer

In the process of five-axis milling, the variability of geometrical parameters of the cutting layer over time is also important, called [4]:

- process kinematics, i.e. angular parameters of the tool axis orientation;

- surface geometry, i.e. variable radii of curvature of the surface being machined.

\section{Cutting force}

The total force exerted by the tool on the workpiece is defined as the resultant of the cutting forces exerted by all cutting blades of the tool $[2,3,6,9]$. The components of the total force are determined by the rectangular projection of this force along the directions of particular movements related to the kinematics of the cutting process being carried out. For five-axis milling with a toroidal miller, the authors [8] give the force distribution shown in fig. 4 . It results from the model of the mechanic cutting force of Altinta-Lee.

In this model, the total cutting force generated in the toroidal milling process can be divided into three components in the tool system, acting on the cross-sectional area of the cutting layer as a function of the angle of temporary position of the cutter's blade.
These components are forces: tangent $F_{\mathrm{t}}(\varphi)$, radial $F_{\mathrm{r}}(\varphi)$ and axial $F_{\mathrm{a}}(\varphi)$. They can be expressed by the following equations:

$$
\begin{aligned}
& F_{\mathrm{t}}(\varphi)=K_{\mathrm{tc}} A(\varphi)+K_{\mathrm{te}} b \\
& F_{\mathrm{r}}(\varphi)=K_{\mathrm{rc}} A(\varphi)+K_{\mathrm{re}} b \\
& F_{\mathrm{a}}(\varphi)=K_{\mathrm{ac}} A(\varphi)+K_{\mathrm{ae}} b
\end{aligned}
$$

where: $K_{\mathrm{tc}}, K_{\mathrm{rc}}, K_{\mathrm{ac}}-$ coefficients of the specific cutting resistance dependent on the cross-sectional area of the machined layer $A(\varphi) ; K_{\mathrm{te}}, K_{\mathrm{re}}, K_{\mathrm{ae}}$ - coefficients of the specific cutting resistance depending on the active length of the cutting edge $b$.

The basic component of the dependence (1) is the crosssectional area of the machined layer $A(\varphi)$ :

$$
A(\varphi)=\frac{a_{\mathrm{p}} f_{\mathrm{z}} \sin (\varphi)}{\sin \kappa_{\mathrm{r}}}
$$

where: $a_{p}$ - axial infeed, $f_{z}$ - blade feed, $\varphi$ - temporary blade position angle, $\kappa_{\mathrm{r}}$ - entering angle.

The dependences (1) and (2) show that the values of the cutting force depend on the geometry of the cutting layer, which is mainly influenced by: axial infeed $a_{p}$, feed per tooth $f_{z}$, angle of the current cutter point $\varphi$ and angle $\kappa_{\mathrm{r}}$. The entering angle $\kappa_{\mathrm{r}}$ determines the geometry of the cutting layer and the cutting force generated in the five-axis machining process. As a result of changing radii of curvature of the machined surface, a change in the entering angle $\kappa_{r}$ between the cutting edge of the cutter blade and the machined surface occurs. The constant change in the entering angle $\kappa_{\mathrm{r}}$, even with constant cutting technology parameters, results in a continuous change of the contact point of the cutter blade with the machined surface, and at the same time changing the cross-sectional area of the cutting layer. As a result of changes in these parameters, changes in the value and direction of action of all components of the cutting force occur. This leads to variable deformation of the elastic tool and workpiece, which has a large impact on the accuracy of the shape.

Subsequently, the course of experiments with selected parameters of the angle of advance $\alpha$ of the tool axis and the radius of curvature $\rho_{1}$ of the surface were determined with the aim of determining the impact of these parameters on the value of the cutting force components.

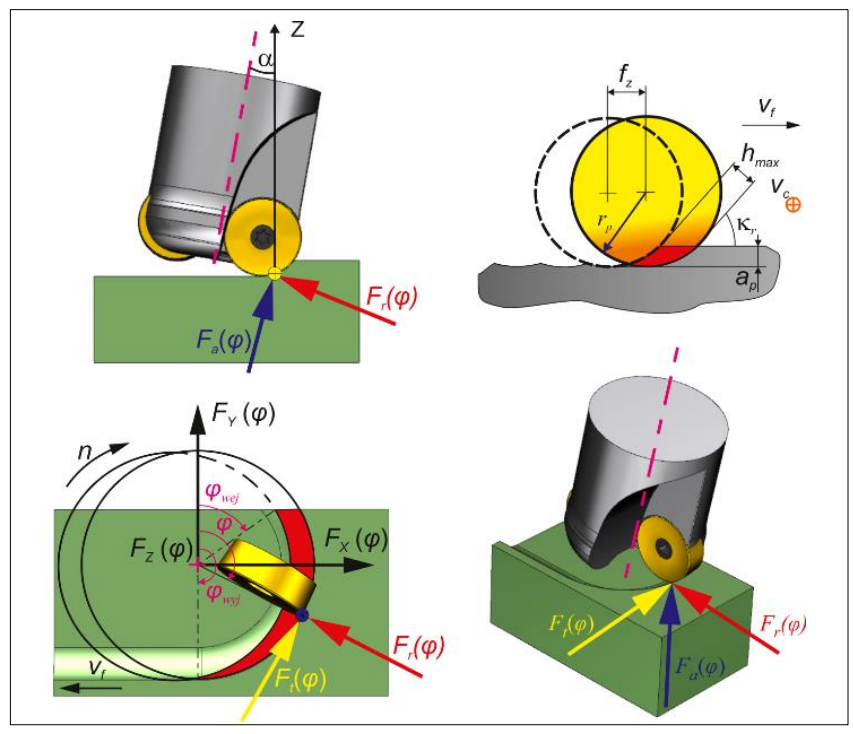

Fig. 4. Distribution of forces in a five-axis milling with a toroidal cutter 


\section{Experimental research}

The construction of the model for experimental research is shown in fig. 5 . The object of these tests was the convex and concave blade surface of the turbine blade. These surfaces were stretched on profiles along their length along the length of the feather. The outline of the blade profiles is described by arcs with different values of the radius of curvature $\rho_{1}$, determined on the basis of the actual geometry of the blade of the turbine blade (fig. 6). The convex and concave surfaces were divided into test areas depending on the radius of curvature $\rho_{1}$ and the angle of advance $\alpha$ (fig. 7). The milling parameters are listed in the table.

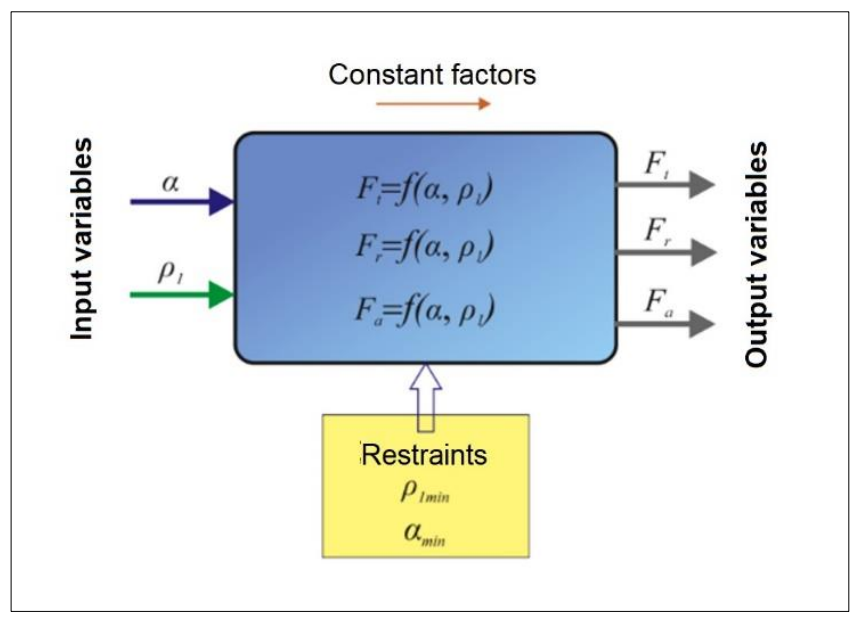

Fig. 5. Building a model of an experimental research object

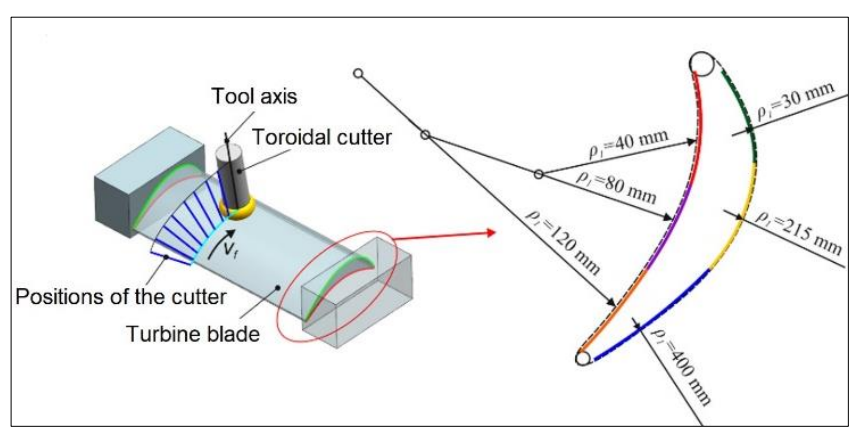

Fig. 6. The subject of experimental research

At each of the machining steps, the constant parameters were: axial infeed $a_{p}$, radial infeed $a_{e}$, feed per tooth $f_{z}$, diameter of the toroidal cutter $D=16 \mathrm{~mm}$ and radius of the circular cutting insert $r_{\mathrm{p}}=4 \mathrm{~mm}$. Moreover, in order to avoid the undercutting of the concave surface, the minimum limiting angle $\alpha_{\min }=7^{\circ}$ for the radius $\rho_{1}=40 \mathrm{~mm}$ of this surface was calculated.

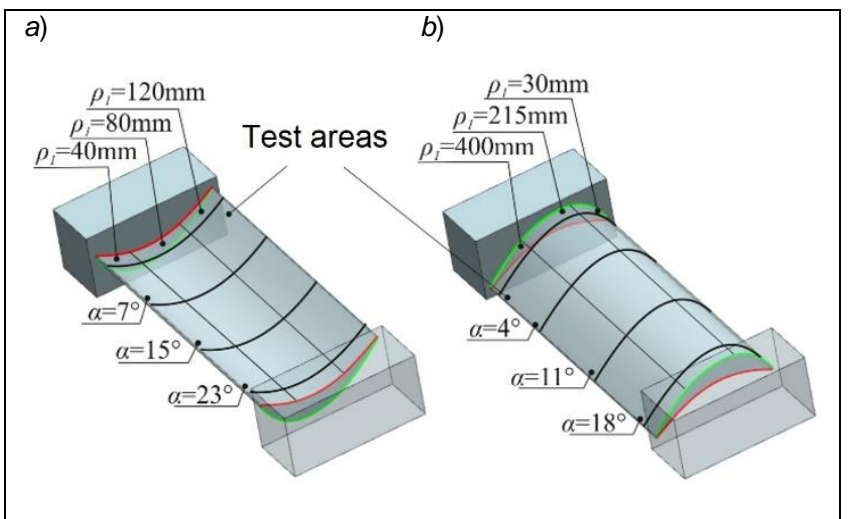

Fig. 7. Test areas depending on the value of the radius of curvature $\rho_{1}$ and the angle of advance $\alpha$ : a) of the concave surface, $b$ ) convex surface
TABLE. Machining parameters

\begin{tabular}{|l|c|c|}
\hline Work area & Convex & Convex \\
\hline$a_{\mathrm{p}}, \mathrm{mm}$ & 0.25 & 0.25 \\
\hline$a_{\mathrm{e}}, \mathrm{mm}$ & 1.5 & 1.5 \\
\hline$f_{\mathrm{z}, \mathrm{mm} / \mathrm{tooyh}}$ & 0.26 & 0.26 \\
\hline$v_{\mathrm{c}}, \mathrm{m} / \mathrm{min}$ & 40 & 40 \\
\hline$\rho_{1}, \mathrm{~mm}$ & $30 \div 400$ & $40 \div 120$ \\
\hline$\alpha,{ }^{\circ}$ & $4 \div 18$ & $7 \div 23$ \\
\hline
\end{tabular}

The test stand and the path for measuring the components of the cutting force were built on the basis of a five-axis milling center CNC 100 DMU MonoBlock from DMG (fig. 8), which is part of the Department of Manufacturing Technology and Automation at the Rzeszów University of Technology.

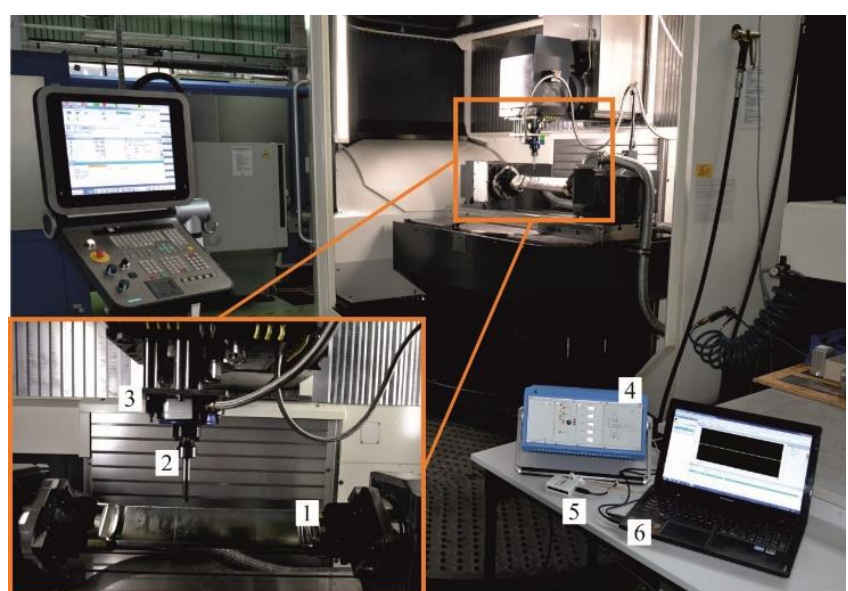

Fig. 8. Measuring path of the cutting force components: 1 workpiece, 2 - toroidal cutter, 3 - four-component rotary dynamometer, 4 - four-channel signal amplifier, 5 - KUSB KEITHLEY 3100 measuring card, 6 - computer with quickDAQ software for viewing, registration and analysis of measuring signals

The machine tool was equipped with NC dividing heads and tools enabling coarse and finishing work of the subject of the research.

To measure the components of the cutting force, a fourcomponent piezoelectric rotary force meter KISTLER type 9123C was used, mounted in the HSK-63A socket of the machine spindle.

The experimental study was subjected to a blade made of Inconel 718 alloy (W. No. 2.4668). The research involved the use of the toroidal milling cutter R300-016B20L-08L Sandvik Coromant with a diameter of $D=16 \mathrm{~mm}$, in which round cutting inserts R300-0828E-PL with radius $r_{\mathrm{p}}=4 \mathrm{~mm}$ were mounted.

The research was carried out in two stages. At the first stage, the process of indexed roughing of the blade surface was carried out. Roughing was not analyzed, and its purpose was to shape the research subject with the assumed allowance for finishing treatment. At the second stage, finishing treatment was carried out.

The research was carried out in accordance with the threelevel static plan of the full PS/DK $3 n$, with the number of repetitions of measurements equal to 3 and with the assumed level of significance of 0.05 . This plan makes it possible to obtain a mathematical model of the studied process in the form of a polynomial function, which is convenient for mathematical analysis and model research [4].

\section{Results}

- Tangential cutting force component. The graphs made on the basis of the obtained model dependences, showing the effect of the radius of curvature $\rho_{1}$ and the 
leading angle $\alpha$ on the course of the tangent component $F_{\mathrm{t}}$, the cutting forces in the treatment of the convex and concave surfaces, are shown in fig. 9 and fig. 10.

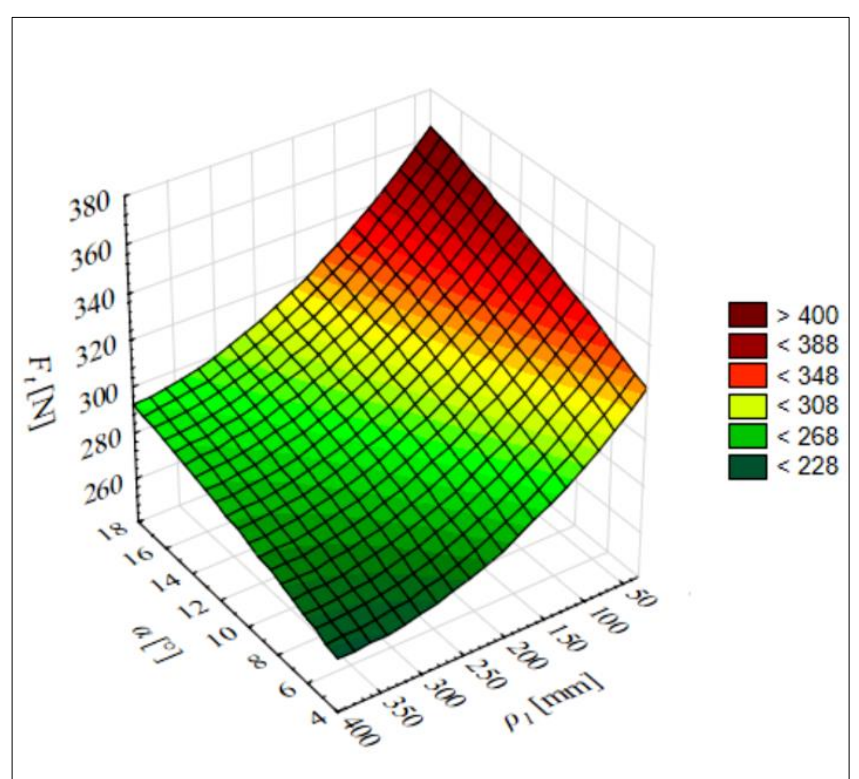

Fig. 9. Influence of the radius of curvature $\rho_{1}$ and the leading angle $\alpha$ on the course of the tangent component $F_{\mathrm{t}}$ of the cutting force in the machining of the convex surface

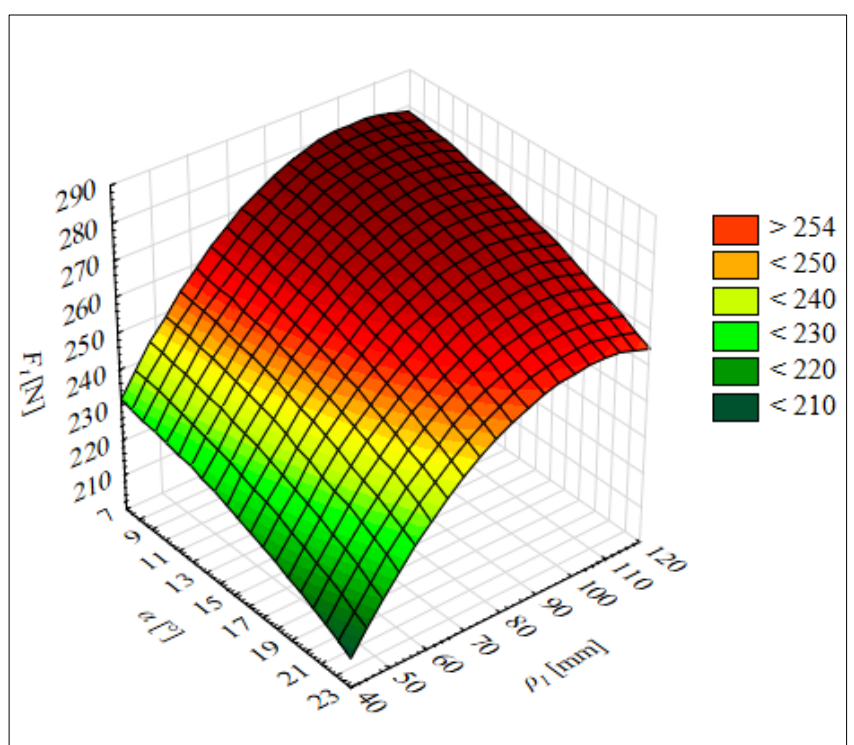

Fig. 10. Influence of the radius of curvature $\rho_{1}$ and the leading angle $\alpha$ on the course of the tangent component $F_{\mathrm{t}}$ of the cutting force in the machining of the concave surface

After analyzing the graphs made, it was found that in the whole range of radius of curvatures $\rho_{1}$ - both the convex and concave surfaces - the value of the component $F_{\mathrm{t}}$ of the cutting force increases with the increase of the radius of curvature $\rho_{1}$. It was also observed that with the increase of the inclination of the milling axis in the direction of feed, the value of the tangent component $F_{\mathrm{t}}$, the cutting force, decreases. This is due to changes in the tool contact zone with the surface being machined and the cross-sectional area of the cutting layer.

- Radial component of the cutting force. Graphs drawn on the basis of the obtained model dependences, showing the effect of the radius of curvature $\rho_{1}$ and the leading angle $\alpha$ on the course of the radial component $F_{\mathrm{r}}$ cutting forces in the treatment of the convex surface and the concave surface are presented in fig. 11 and fig. 12, respectively.

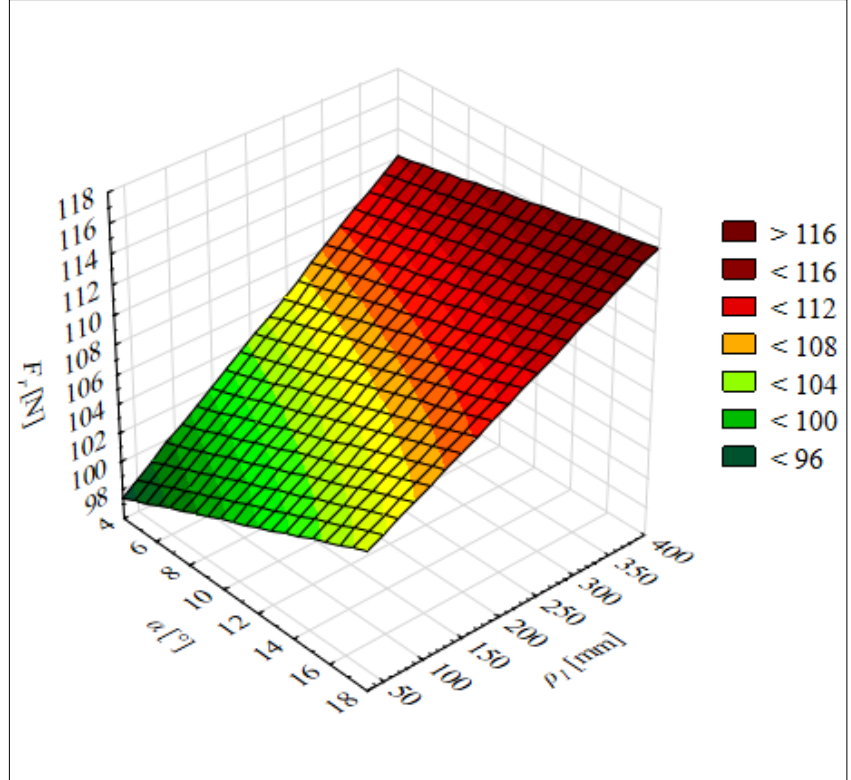

Fig. 11. Influence of the radius of curvature $\rho_{1}$ and the angle of advance $\alpha$ on the course of the radial component $F_{\mathrm{r}}$ of the cutting force in the machining of a convex surface

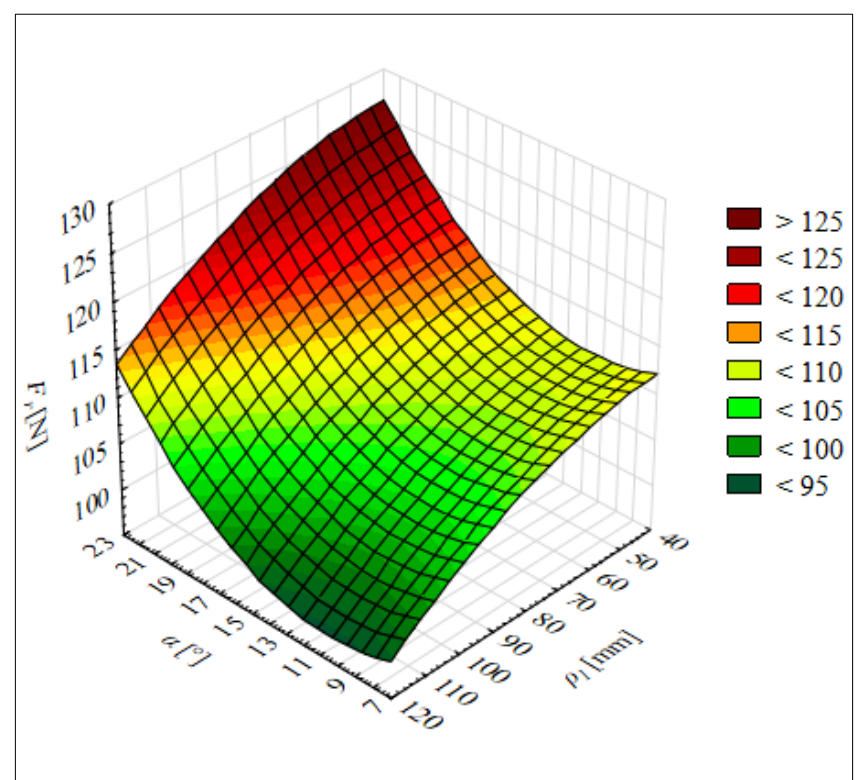

Fig. 12. Influence of the radius of curvature $\rho_{1}$ and the leading angle $\alpha$ on the course of the radial component $F_{\mathrm{r}}$ of the cutting force in the treatment of the concave surface

Presented graphs show that in the case of convex surface treatment, the value of the component $F_{\mathrm{r}}$ increases with the increase of the parameter $\rho_{1}$ in the entire adopted analysis range, and decreases in the case of concave surface treatment. The increase in $F_{r}$ force during the machining of the convex surface may result from the extension of the cutter blade contact line with the profile of the surface being machined and the increase of the cutter's arc angle. With increasing the inclination of the milling axis in the direction of feed, the value of the radial component $F_{r}$ cutting force increases in the machining of both types of surface. This is due to the increase in the cross-sectional value of the cutting layer.

- Axial component of the cutting force. The diagrams created on the basis of the obtained model dependences, showing the effect of the radius of curvature $\rho_{1}$ and the leading angle $\alpha$ on the course of axial component $F_{\mathrm{a}}$ of the cutting force in the treatment of the convex and concave surfaces, are shown in fig. 13 and fig. 14. 


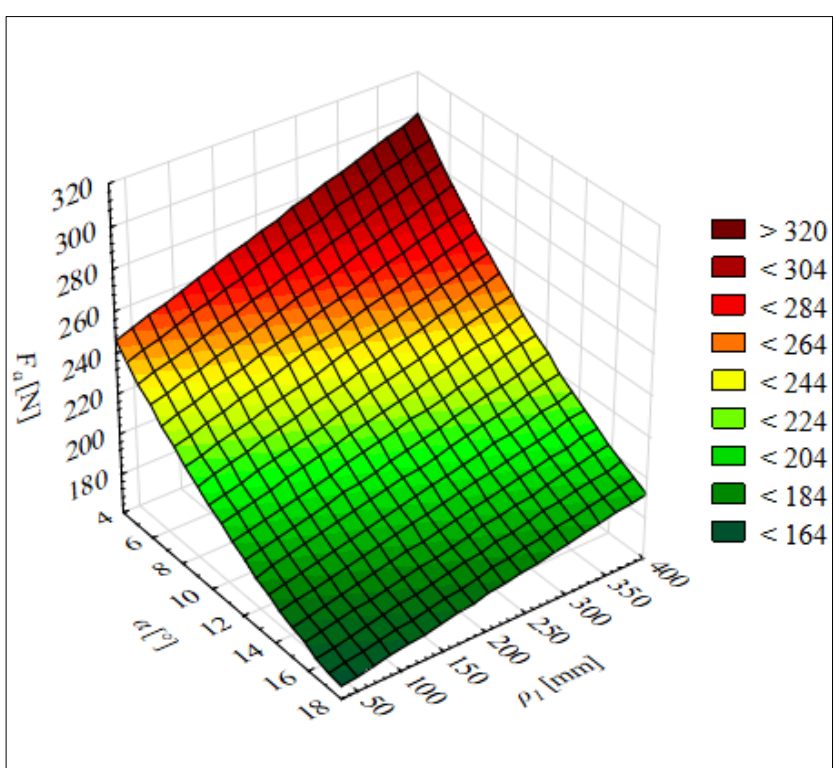

Fig. 13. Influence of the radius of curvature $\rho_{1}$ and the leading angle $\alpha$ on the course of axial component $F_{\mathrm{a}}$ of the cutting force in the machining of a convex surface

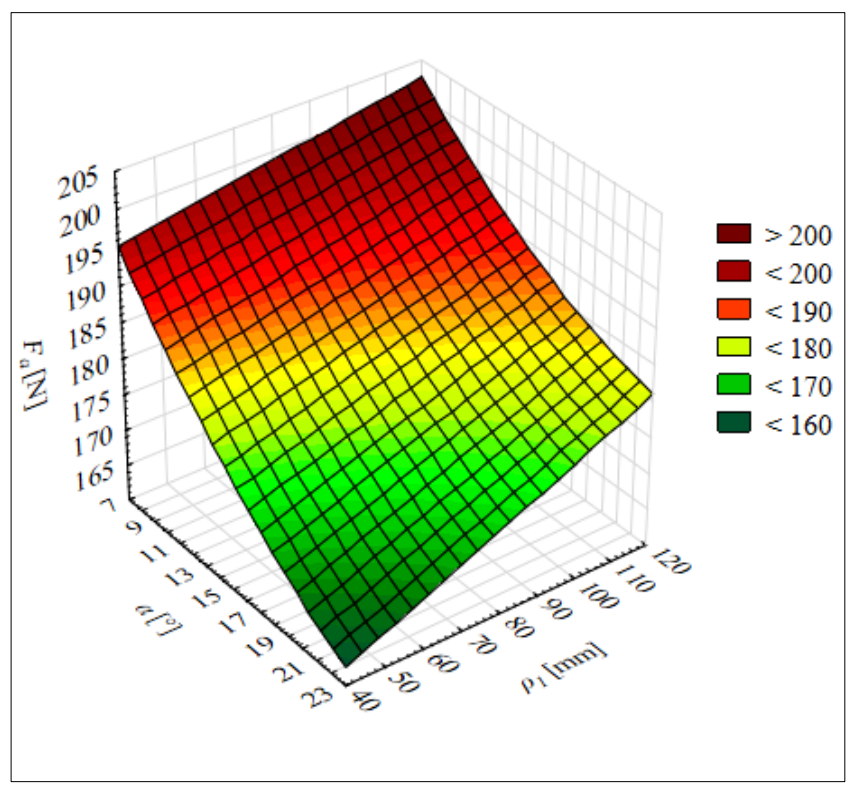

Fig. 14. Influence of the radius of curvature $\rho_{1}$ and the leading angle $\alpha$ on the course of the axial component $F_{\mathrm{a}}$ of the cutting force in the machining of the concave surface

From these graphs, the value of the axial component $F_{\mathrm{a}}$ of the cutting force increases with the increase of the radius of curvature $\rho_{1}$, while the increase in the angle of the cutting axis $\alpha$ results in a reduction of the axial component $F_{\mathrm{a}}$ of the cutting force in the case of machining both surfaces. By comparing the obtained axial courses $F_{\mathrm{a}}$ of the cutting forces as a function of the advance angle $\alpha$ and the radius of curvature $\rho_{1}$, it can further be stated that when machining the convex surface of the axial component $F_{\mathrm{a}}$ the cutting forces are greater than when machining the concave surface.

\section{Conclusions}

Based on the experimental tests carried out and the analysis of the results obtained regarding the components of the cutting force, it can be concluded that as the radius of curvature $\rho_{1}$ in the tested range increases, the contact zone between the tool and the work surface - both convex and concave, increases. As a consequence, this leads to an increase in the cutting force components. This is due to the fact that along with the increasing contact zone, the cross- sectional area of the cutting layer increases and, consequently, the cutting forces increase. However, as the angle of advance $\alpha$ increases, the contact zone decreases. The result is a reduction in the cross-cut of the cutting layer and thus a decrease in the value of cutting forces. An exception is the radial component $F_{\mathrm{r}}$ of the cutting force, the value of which increases slightly as the angle of advance $a$ increases.

It was also found that the component cutting forces generated during the process of machining the convex and concave surface can be significantly influenced by the kinematic parameter of the advance angle $\alpha$. Presumably, this parameter can also indirectly affect the shape deviation $\Delta_{\mathrm{k}}$ and surface roughness parameters, but to confirm this, it is necessary to carry out research in this direction.

To sum up: the values of the leading angle $\alpha$ in the treatment of the convex or concave face of the turbine rotor blade should be changed continuously in accordance with the change in the radius of curvature $\rho_{1}$ of the surface profile to be processed.

\section{REFERENCES}

1. Berglind L., Plakhotnik D., Ozturk E. "Discrete Cutting Force Model for 5-Axis Milling with Arbitrary Engagement and Feed Direction". Procedia CIRP. 58 (2017): pp. 445-450.

2. Boz Y., Erdim H., Lazoglu I. "Modeling Cutting Forces for 5-Axis Machining of Sculptured Surfaces". Advanced Materials Research. 223 (2011): pp. 701-712.

3. Burek J., Gdula M., Żyłka Ł., Płodzień M. „Wpływ orientacji osi frezu toroidalnego na składowe siły skrawania w pięcioosiowej obróbce łopatki turbiny ze stopu Inconel 718". Mechanik. 8-9 (2015): pp. 764-774.

4. Gdula M.: „Proces symultanicznego pięcioosiowego frezowania powierzchni złożonych frezem toroidalnym". Praca doktorska. Rzeszów, 2017.

5. Gdula M., Burek J., Żyłka Ł. "Cross section of the cutting layer in simultaneous five-axis machining of sculptured surfaces". Archives of Mechanical Technology and Automation. 34, 4 (2014): pp. 25-36. 6. Gdula M., Burek J., Żyłka Ł., Turek P. "Analysis of accuracy of the shape of sculptured surfaces in simultaneous five-axis machining of parts made from difficult to machine materials used in aviation technology". Archives of Mechanical Technology and Automation. 34, 4 (2014): pp. 11-24.

7. Gilles P., Monies F., Rubio W. "Optimum orientation of a torus milling cutter: Method to balance the transversal cutting force". International Journal of Machine Tools and Manufacture. 47 (2007): pp. 2263-2272.

8. Luo S., Dong Z., Jun M. "Chip volume and cutting force calculations in 5-axis CNC machining of free-form surfaces using flat-end mills". International Journal of Advanced Manufacturing Technology. 90 (2017): pp. 1145-1154.

9. Ozturk E., Budak E. "Modelling of 5-Axis Milling Forces".

Machining Science and Technology. An International Journal. 11, 3 (2007): pp. 287-311.

Translation of scientific articles, their computer composition and publishing them on the website www.mechanik.media.pl by original articles in Polish is a task financed from the funds of the Ministry of Science and Higher Education designated for dissemination of science.

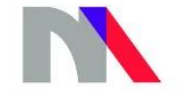

Ministry of Science and Higher Education Republic of Poland 